TITLE:

\title{
The internationalization of engineering education: A tale of two countries
}

$\operatorname{AUTHOR}(\mathrm{S}):$

Hipel, KW; Okada, N; Fukuyama, K

\section{CITATION:}

Hipel, KW ...[et al]. The internationalization of engineering education: A tale of two countries. IEEE TRANSACTIONS ON SYSTEMS MAN AND CYBERNETICS PART CAPPLICATIONS AND REVIEWS 2003, 33(1): 137-148

\section{ISSUE DATE:}

2003-02

URL:

http://hdl.handle.net/2433/40010

\section{RIGHT:}

(c)2003 IEEE. Personal use of this material is permitted. However, permission to reprint/republish this material for advertising or promotional purposes or for creating new collective works for resale or redistribution to servers or lists, or to reuse any copyrighted component of this work in other works must be obtained from the IEEE. 


\title{
The Internationalization of Engineering Education: A Tale of Two Countries
}

\author{
Keith W. Hipel, Fellow, IEEE, Norio Okada, and Kei Fukuyama
}

\begin{abstract}
Two international exchange programs in engineering between universities in Japan and Canada, are described in order to explain the significant benefits gained by the undergraduate and graduate students, as well as the academic staff who participate, and to highlight key principles generally followed in the design and execution of exchange programs. One notable and successful engineering exchange program is between the University of Waterloo, located in Southern Ontario, Canada, and Tottori University in Japan, while the other is between the University of Waterloo and Kyoto University in Japan. Both of these programs include foreign students taking courses for credit or audit at the host university, and, for the case of graduate students, also receiving guidance in their research. Moreover, upon completion of one academic semester in Japan, all of the undergraduate Waterloo students studying at Tottori University are employed in Japanese industry for three to four months before returning to Canada. Of paramount importance to the education of the participating undergraduate and graduate students is the opportunity to learn, by first-hand experience, the language and culture of a foreign country. In fact, one of the key findings of a survey completed by Canadian and Japanese students who took part in the exchange programs, is that living in a different culture greatly enhanced their own personal development. The addition of this international perspective to a solid education in engineering opens many doors of opportunity for exchange program alumni, who are well prepared to fully participate in the global marketplace of the 21st century, and to assist society in responsibly reaching an equitable and sustainable future.
\end{abstract}

Index Terms-Cultural awareness, engineering education, foreign work experience, international exchange programs, pedagogy.

\section{SONG OF GLOBALIZING ENGineERING EdUCATION}

D URING the second half of the 16th century, when the Ashikaga shogunate was collapsing, three great leaders emerged to unite Japan: Oda Nobunaga, Toyotomi Hideyoshi, and Tokugawa Ieyasu. The different personalities of these remarkable visionaries is aptly portrayed in a verse known throughout Japan:

What if the bird will not sing?

Nobunaga responds, "Kill it!"

Hideyoshi answers, "Make it want to sing."

Ieyasu says, "Wait."

Manuscript received August 17, 2002; revised December 12, 2002.

K. W. Hipel is with the Department of Systems Design Engineering, University of Waterloo, Waterloo, ON N2L 3G1, Canada (e-mail: kwhipel@engmail.uwaterloo.ca).

N. Okada is with the Integrated Management for Disaster Risk, Disaster Prevention Research Institute, Kyoto University, Kyoto 611-0011, Japan.

K. Fukuyama is with the Department of Human/Social Information Sciences, Tohoku University, Sendai 980-8577, Japan.

Digital Object Identifier 10.1109/TSMCC.2003.809356
Our philosophy in founding and running two exchange programs, between Canada and Japan, is closely aligned to that of Hideyoshi, whose able leadership inspired a prosperous period of renaissance at a crucial time in Japanese history [11]. At our universities in Japan and Canada, engineering students are regularly encouraged to add an international and cultural dimension to their education by volunteering to participate in exchange programs between our two countries. Just as the late 16th century Japan saw many dramatic changes take place, so too, the world today is undergoing fundamental transformation, as societies interact globally in an ever-expanding international marketplace. We can think of no better experience for our students to learn and adapt to this new global order than by living, studying, and even working in a foreign country as part of their undergraduate or graduate university education. Academic staff are also able to enhance their research and teaching expertise, while gaining international experience, by helping to run exchange programs and by visiting foreign universities.

The main objectives of our paper are to explain how our Canada/Japan exchange programs have greatly enriched the education and cultural understanding of our students, how they provide a vehicle for our academic staff to expand their international academic projects, and how the wisdom we have garnered can be encapsulated into a set of principles for designing and operating a successful international exchange agreement. As explained in detail in Section IV, two international exchange programs between the University of Waterloo, located in Southern Ontario, Canada, and Tottori University, located in Japan, as well as a second one between Waterloo and Kyoto University came into operation in 1988 and 1992, respectively. At the present time, only graduate students from the two Japanese universities have studied at Waterloo, while Waterloo has sent only graduate students in engineering to Kyoto University. Additionally, each year undergraduate engineering students from Waterloo study the first semester of their third year at Tottori University followed by a three to four month workterm in companies located throughout Japan. However, it should be pointed out that these two programs are open to both undergraduate and graduate students in engineering at all three participating universities. We are pleased to report that all of the 132 Canadian and Japanese students who have lived abroad under these two programs, have successfully completed the program requirements.

The main objective of the international exchange programs is to furnish our students with the opportunity to learn the culture and language of another country, by means of hands-on experience. Within the classroom setting, students are able to compare the differences in pedagogy between Canada and Japan. A 
Japanese student, for instance, who is taking a course at Waterloo, may discover the advantages of learning in the highly interactive teaching environment between a professor and his students. A Canadian student, on the other hand, may come to realize how highly the Japanese value education, and in particular, the engineering education. As a matter of fact, the technical contents of equivalent engineering courses taught in Japan and Canada are identical, but the academic atmosphere in which they are delivered are quite different and can only be fully comprehended through actual experience. In the Japanese workplace, the Waterloo students employed by various industries are able to personally observe the admirable work ethic of the Japanese, as well as the effective ways in which they cooperate to complete projects.

Besides work and study, mingling with a wide variety of people on a daily basis in another country, visiting historical sites and museums, attending musical festival and plays, and simply going out with foreign friends to have a good time, all contribute to a unique cultural learning experience. Undoubtedly, this valuable foreign exposure will better equip our students to create their own distinctive careers as competent professional engineers within their home countries, as well as compete in the international arena. As recently stated by both the Canadian Council of Professional Engineers and the Canadian National Committee of Deans of Engineering, "Engineering students should be provided with opportunities to develop their competencies in at least one language and culture other than their own at a level appropriate for engineering practice. This objective may be achieved by a combination of formal studies and work in Canada and abroad."

In [2]Deshayes et al. edited a set of seven interesting papers on systems engineering education that included contributions on desirable characteristics of systems engineering education curriculae, experiences with specific types of education in systems engineering, and future developments. In their guest editorial, Deshayes et al.[2] point out that the international exchange of students is one of a number of relevant topics that could also have been addressed within the special issue. Moreover, Sage [7] declares that a major ingredient of engineering education is the "appreciation of different cultures and business practices, and understanding that engineering is now global." Accordingly, international and cultural dimensions of engineering education are considered here, based upon valuable experiences gained by the authors, their students, and other colleagues actively involved in the international exchange programs between Japan and Canada. As a matter of fact, although participation in student exchanges is open to all engineering students at Waterloo, Tottori, and Kyoto Universities, the majority of students who took part were enrolled in the systems engineering programs.

Following an overview of the three universities participating in the exchange programs, Section III-A outlines the main components that we believe should be incorporated into exchange program agreements, such as the Waterloo/Tottori, and Waterloo/Kyoto exchange programs described in Sections III-B and $\mathrm{C}$, respectively. The main benefits gained by all exchange program participants, the remarkable careers of some of our exchange program alumni pursuing rewarding careers with international companies, or in academia, and the results of a survey completed by Canadian and Japanese participants, are all presented in the first three parts of Section IV. With the information provided through Section IV-C, the reader should be in a position to fully appreciate the principles for designing, operating, and improving exchange programs in general, which we formulate in Section IV-D. In a technical report [4], the authors provide further details regarding the founding of the exchange programs, as well as the history of the three participating universities.

\section{TRI-UNIVERSITY CULTURES}

\section{A. Common Traits}

In Section III, two international exchange programs between Canada and Japan are described in detail —one between the University of Waterloo and Tottori University, and the other between Waterloo and Kyoto University. The receptiveness of a university to embrace and nourish innovative, and sometimes radically different educational programs is directly dependent upon the culture and outlook of the university community. Therefore, the objective of this section is to provide an overview of the history, culture, and strengths of all three universities with special emphasis on each university's policies and attitudes toward international activities, such as, exchange programs. The world wide web addresses for the three universities are also provided with the references.

At each of the universities, academic innovations initiated and implemented at a "grass-roots" levels, such as departments and faculties, are encouraged and supported throughout the university, including the provision of overall university-level administration and coordination. For the case of the two exchange programs discussed in this paper, the agreements are between the faculties of engineering in both countries, and each agreement was approved by the presidents of the two respective universities. Because these two exchange programs are designed for use by Japanese and Canadian students in engineering, one might assume that they are encouraging only "technical" education. Although partially true, the most important aspect of the exchange is in fact, the cultural component. Within each university, potential exchange students are advised to take both cultural and language courses with respect to the country they will be visiting. Hence, interaction between engineering and academic units in the arts automatically takes place at each university. Furthermore, once exchange students arrive at their foreign destinations, they ecome totally immersed in the culture of the country. Finally, at all three universities, student participation in exchange programs is considered to be one of the most valuable, and extremely beneficial, forms of education to his or her future career, and therefore each student is given full academic credit for academic activities completed during an exchange. Faculty and staff members who devote their valuable time to run these programs also receive complete credit for their contributions. For example, at the University of Waterloo, directing an exchange program is an important factor in assessing the overall academic performance of a faculty member to determine his or her annual merit increase in salary. 


\section{B. University of Waterloo: Canada's Most Innovative University}

In its annual assessment of universities across Canada, Maclean's, Canada's national weekly news magazine, has consistently ranked the University of Waterloo as first in the country according to the three criteria of most innovative, leaders of tomorrow, and best overall. At its founding in 1957, the University of Waterloo became a pioneer in university education by launching the cooperative education, or "co-op" system whereby all undergraduate students in engineering combine formal classroom education with learning on the job. Hence, co-op students are required to study for one semester, followed by a semester working in industry, government, or an in-service sector, and they are to continue this alternating process until the completion of their undergraduate program in engineering, which takes one semester less than five years. This type of revolutionary education attracts the brightest students in the country, as well as gifted professors from around the world who want to teach and carry out leading edge research within this stimulating academic environment.

At the present time, the University of Waterloo has about 10000 students in 80 co-op programs in partnership with 2500 employees, making its co-op educational program the largest in the world. The university offers academic programs in over fifty disciplines across six faculties, consisting of Engineering, Mathematics, Science, Arts, Environmental Studies, and Applied Health Sciences, which has a total of over 17000 full-time and 7000 part-time students. The Engineering Faculty, the most prestigious and largest in Canada, has over 4000 undergraduate and graduate students. The Faculty of Mathematics, the only one of its kind anywhere in the world, has more than 3000 undergraduate and graduate students studying wide areas of mathematics, ranging from pure mathematics to computer science.

As with co-op education, the Faculty of Engineering at the University of Waterloo was a pioneer in fostering student exchange programs, which proved to be its next grand educational innovation. The first exchange program was started with the University of Braunschweig, Germany, in 1980, while the exchange agreements with Tottori and Kyoto Universities were initiated in 1987, and 1992, respectively. The popularity of these exchange programs soared, and presently, Waterloo has the most comprehensive set of engineering exchange programs in Canada, involving 39 institutions in 16 countries located in Asia, Europe and Mexico (see [5] for an overview and Waterloo's home page). Each program has at least one coordinator, or director, based in Waterloo matched with his or her counter-part at the respective foreign university. Most exchange programs are open to students in the five engineering departments at Waterloo that possess Bachelor's, Master's, and Ph.D. programs - chemical, civil, electrical and computer, mechanical, and systems design engineering. Although individual coordinators usually receive secretarial and other staff support from their departments, the large number of programs necessitate the need for overall coordination and support at the faculty level via the Office of Student Exchanges in Engineering, which houses the director and support staff.

All Waterloo engineering students who participate in official exchange programs are given full academic credit for all courses successfully completed at foreign institutions, as well as their co-op work experience. Moreover, Waterloo students who take part in an exchange program can obtain academic credit for an Option in International Studies in Engineering by finishing specific courses in languages, international politics, culture, economics and other related areas. At the university level, Waterloo now has an International Programs Office to assist in the management of collaborative programs throughout the university.

Cultural and language courses related to a foreign country with an exchange program are usually taught within academic units located in the Faculty of Arts and four Church Colleges affiliated with the University of Waterloo. Participation in these courses, by engineering and other students involved in international exchanges, has led to the cross-fertilization of ideas and strengthening of ties between the arts and the technical sciences within the university. With respect to students going to or coming from Japan, Korea, or China, Renison College has made solid academic contributions to their education. In particular, through its program in East Asian Studies, Waterloo students who wish to go to Japan can study as many as five courses in the Japanese language, as well as take Asian cultural courses. Japanese and other foreign students coming to Waterloo can study English as a second language at Renison. Finally, since 1995, Renison College has held an annual East Asian Festival which highlights events connected to business, culture, and education, including international exchanges.

\section{Tottori University: An Eagle in Full Flight}

Tottori University was established on May 31, 1949 and is one of the ninety-seven national universities in Japan. At present, the university encompasses the faculties of Engineering, Medicine, Education, and Agriculture, and has graduate schools in all of these faculties. The Department of Social Systems Engineering, which heads the Waterloo/Tottori Exchange Program, was started in 1985 within the Faculty of Engineering and was the first of its kind in Japan. The College of Medical Care Technology and the Arid Land Research Center are affiliated with the university. Tottori University has two campuses. The Koyama Campus is located in Tottori City, the capital of Tottori Prefecture, and houses all of the faculties except Medicine, which is situated at the sister campus in the city of Yonago. There are about 625 full-time teaching staff, 865 administrative staff, and 6000 students at Tottori University.

Tottori Prefecture is situated on the western side of Honshu Island adjacent to the Sea of Japan. The prefecture's capital, Tottori City, was built on the delta of the Sendai River, and faces the Sea of Japan to the north and beautiful mountain ranges to the south. The Japanese word Tottori actually means "bird catcher." In reality, however, Tottori University is in full flight toward its academic goals with no intention of being put into a cage. Moreover, even though Tottori University is located in a prefecture with a relatively small population of about 600000 people, it has worked diligently to create high-quality academic programs which attract gifted students from many parts of Japan, including applicants from the heavily populated Kansai, and Kanto areas. 
To promote international exchanges, in 1985, Tottori University established the International Exchange Commission. As part of their undergraduate degree requirements, engineering students at Tottori University must take eight English courses from the Faculty of Education. Although Japanese students usually do not take English courses at the graduate level, visiting students studying at Tottori University, including Waterloo Exchange Students, take Japanese language and cultural courses from the Faculty of Education. This faculty also offers special sessions for any students wishing to practice writing TOEFL (test of English as a foreign language) examinations. The aforesaid and other activities encourage academic interaction between the Faculties of Engineering and Education.

\section{Kyoto University: The Pearl of the Orient}

Kyoto University is situated in the ancient city of Kyoto, which is considered to be one of the most beautiful and culturally important cities in the world. The university was established in 1897, as an imperial university, and has grown into a large, prestigious university which now has about 14000 undergraduate students, 7000 graduate students, including 1000 foreign students, 2700 teachers, and 2500 administrative staff. In fact, Asian Week ranks Kyoto University as the best overall university in Asia. Currently, the university boasts ten faculties, thirteen graduate schools, thirteen affiliated research institutes, and seventeen research and services centers. In 1996, the Faculty of Engineering was reorganized into six schools consisting of Global Engineering, Architecture, Engineering Science, Electrical and Electronic Engineering, Informatics and Mathematical Science, and Industrial Chemistry. The Graduate School of Engineering is comprised of twenty-one departments and three research schools, which are housed within the six schools. For example, the School of Global Engineering contains the Departments of Civil Engineering, Civil Engineering Systems, Earth Resources Engineering, Environmental Engineering, and Global Environmental Engineering. The number of undergraduate and graduate students in the Faculty of Engineering are approximately 4500 and 2000, respectively. At the university level, the Committee for International Academic Exchange is an advisory body to the President and deliberates on internal matters related to education and research, as well as student exchange programs.

Because they are obliged to take four compulsory English courses as part of their undergraduate degree, Japanese graduate students in engineering who wish to go to the University of Waterloo as part of the exchange program, usually do not take additional English courses as graduate students. As a matter of fact, because the grammatical structure of Japanese and English is radically different, and some sounds such as the letter " $r$ " are difficult to pronounce, native Japanese speakers can only approach fluency in English after they have had the opportunity to become totally immersed in an English-speaking culture. Therefore, the exchange program with Canada offers Japanese students an ideal avenue to become conversant in English. Conversely, Canadian students studying in Japan can learn to speak Japanese well, although writing Japanese, using a mixture of Kanji (about 2000 Chinese characters) and two phonetic alphabets of 46 letters each (hiragana and katakana), is extremely dif- ficult, unless the student can already write in Chinese or Korean. Hence, in Japan, both foreign and Japanese students in engineering are allowed to write their Master's and Doctoral theses in English. Another reason for permitting research documents to be written in English is because it is the "lingua franca" of science, engineering, and technology.

\section{Two CANADA/JAPAN EXCHANGE PROGRAMS}

\section{A. Overall Design}

The next two subsections provide the specific recipes that make the University of Waterloo/Tottori University, and the Waterloo/Kyoto University exchange programs, respectively, such academic and cultural feasts for the participants. In order for these, and other academic exchange programs to be a culinary success, however, there are a few key ingredients that must be included in the particular recipe for a given exchange agreement. To abide by the principle of universality, both undergraduate and graduate student, as well as academic staff, should be able to take part in the exchange program. Students from a "home" university who go to a foreign country to study at a "host" university should be granted the same rights and privileges as students in the same discipline at the host university. Hence, given that the students from the home university have the proper academic background and qualifying grades for admission to the host university, the visiting students should be able to take, for credit or audit, any suitable courses they wish, and on their successful completion, they will automatically be granted credit for these courses at their home university. Moreover, visiting students should be granted full access to all campus facilities available to local students at the host university, including residences, libraries, cafeterias, and sporting complexes.

Exchange agreements should be self-supporting, and hence, participating students are responsible to pay all their own costs such as, traveling, health coverage, tuition, and living expenses. Depending upon the agreement, however, the exchange students should pay the usual tuition fees at either their home university, or the host university at the same amount. With respect to the two Canada/Japan exchange programs, scholarships may be available for some of the students to help cover their costs, but interested students should be informed that they will probably have to use their own resources to take care of expenses.

To avoid problems, the home university sending exchange students to the host university should carefully decide whether or not students have adequate language skills and suitable academic achievements to study at the host university. The host university may, of course, only be able to accept a certain number of students each year, but beyond that stipulation, it should not refuse entry to any student whom the home university considers eligible for participation.

By definition, research and teaching at the Master and Doctoral levels are international in scope. Professors and graduate students, for example, complete original research that is published in international journals, conference proceedings, and books, and their original work is often presented by them at international meetings. Moreover, the latest research findings from around the globe are incorporated into graduate courses. However, in general, education at the undergraduate level does 
not possess strong international components like its graduate counterpart. Therefore, some main objectives of exchange programs are to internationalize undergraduate education and further strengthen the internationalization of graduate education, by allowing students to study, and perhaps also, to work in foreign countries as part of their degree requirements.

Both of the Canada/Japan exchange programs described in Sections III-B and C were established as a result of prior research connections among faculty members at the Japanese and Canadian universities. To encourage other academic staff at participating universities to take part in joint research and teaching projects, these activities should be included within the agreement. A joint research project, for example, may provide scholarships with which to support graduate students participating in the exchange program, and cover the traveling and living expenses of faculty members who visit a host university.

The foregoing main ingredients of a successful exchange program, should be carefully mixed together in the required proportions and cooked in the appropriate manner to provide an academic banquet that satisfies the particular tastes of all the individuals involved. Moreover, as the outlook and appetites of the participants change over time, the menu and accompanying recipes can be suitably updated in a dynamic manner to best meet the ongoing academic, cultural needs, and other rising challenges.

\section{B. Waterloo/Tottori Exchange Program}

On November 16, 1987, the final version of an exchange program agreement between the University of Waterloo and Tottori University was signed by the Presidents and Deans of Engineering of both universities. This agreement was first proposed by Hipel of Waterloo and Okada, then a faculty member at Tottori University. These two relatively young and dynamic universities, the academic cultures of which are described in Sections II-B and C, for Waterloo and Tottori, respectively, entered into a meaningful relationship that, over the years, would mature and expand in a way significantly beneficial to the students, the academic staff, and the local communities in both countries. Currently, a total of 80 undergraduate students in engineering from the University of Waterloo have spent nine months in Japan in order to complete one academic term at Tottori University and also to obtain subsequent work experience in Japanese industry. They also traveled to many exciting locations in Japan and sometimes to other parts of Asia, learned to speak Japanese, and became completely immersed in the fascinating Japanese culture. As of May 21, 2002, Japanese Master's students have come to the University of Waterloo to study for two academic terms, experience Canadian culture, become fluent in English, and take the opportunity to explore Canada. Within Sections III-B-I and II, descriptions are given of the specific schedules and components of the operational aspects of the exchange programs as they affect the participating Waterloo and Japanese students. In Sections IV-A and $\mathrm{B}$, individual success stories of a number of past participants are highlighted.

Tottori Program for Waterloo Students: Because the academic year at Japanese universities starts in early April, about six undergraduate Waterloo students arrive in Tottori around this time each year to study courses for the first semester of their third year, which concludes at the end of July. Although most of the exchange students have come from the Department of Systems Design Engineering at the University of Waterloo, students from electrical and computer, mechanical, and civil engineering have also participated. Each visiting student is given a study desk in the research laboratory of a professor working in his or her academic field who acts as the student's mentor while at Tottori. The professor's graduate and fourth year undergraduate students share the same study room and can assist the Canadian student in his or her academic studies, as well as help the student become acclimated to Japanese culture. Canadian students take the equivalent of the same five courses that they would normally study at Waterloo. If a required course is being taught at Tottori University to Japanese students during the April to July term, the Canadian students naturally attend this course. However, they may be given some extra lectures in English, and they are always permitted to write their homework, reports, and final examinations in English. In order to assist the Japanese instructor, he or she is provided with the course outline for the equivalent Waterloo course, along with the course textbook, written in English. When a stipulated course is not currently being taught to Japanese students, a professor kindly delivers a course in English for the benefit of the Waterloo students.

Although the cost of living in Japan is high, Canadian exchange students usually do not have to spend more money than they would in Canada for a variety of reasons. First, the Canadians pay their tuition at the host university, Tottori, which charges approximately the same fees as Waterloo (about $\$ 1500$ Canadian per term). Secondly, the Waterloo students are provided with affordable accommodation at the Tottori University International House. In addition, they can cook their own meals in their residences, or else, dine at the inexpensive cafeterias on campus, or at reasonably-priced restaurants located in close proximity to the university. Finally, during the past seven years, many of the Canadian students have received generous Japanese scholarships, such as the one from the Association of International Education in Japan.

The Canadian students enjoy a busy social program, as they are encouraged by the graduate students in their laboratories, as well as their undergraduate classmates, to join campus clubs such as, karate, singing, and rugby. These clubs meet at least once a week. One of the female Canadian students surprised the Japanese by joining the rugby team, while another Canadian female impressed them by receiving her black belt in karate. After completing their examinations at the end of July, the Canadians have the unique opportunity to travel for six weeks throughout Japan or elsewhere in the Orient, where they can view interesting historical sites, hike in national parks, and see cultural treasures such as ancient temples and precious artwork.

In mid-September, each student commences his or her employment at a Japanese company that is usually located in a large metropolitan area such as Tokyo or Osaka. Waterloo students have worked for enterprises such as Hitachi in Yokohama, Nihon Suido Consultants in Tokyo and Nissin Systems in Kyoto. As pointed out in Section II-B, workterm 
experience is compulsory for all Waterloo engineering students and is part of their degree requirements. Many of the jobs are obtained through the traditional "networking system". A Tottori professor may, for example, call an alumnus of Tottori University working in industry and suggest that a Waterloo student be hired by that person's company. To date, all 80 participating students have had meaningful employment provided for them in Japan. In the workplace, Waterloo students are able to observe the world famous Japanese work ethic in practice, learn valuable technical and communication skills, as well as join after-work social events. By the time the Waterloo students return to Canada, usually shortly before Christmas, they possess a storehouse of memorable experiences that will undoubtedly influence the rest of their lives. In early January, they commence the second semester of their third year at the University of Waterloo.

Waterloo Program for Tottori Students: Each year in midSeptember, two or three Master's students from Tottori University arrive at the University of Waterloo to study during the fall (September-December) and winter (January-April) academic terms. Although the programs are open to all engineering students, so far all of the Japanese students have come from the Department of Social Systems Engineering. The students are allowed to select graduate courses for which they have the proper background. During each of the two terms, students normally take two courses for credit, and perhaps an extra course for audit. Moreover, ambitious students often take the opportunity to examine ongoing research activities in their fields of interest at Waterloo. Their Master's theses are completed upon their return to Tottori University.

All lectures and examinations are in English, and due to the significant differences in the grammatical structures of the two languages, the best way for the Japanese to learn English is to use the language in their daily interactions with others. Accordingly, there is a marked improvement in the English language proficiency of the Japanese students after the completion of just two semesters at Waterloo. Many of the students voluntarily take English language courses at Renison College. Finally, to further strengthen his or her linguistic skills, each Japanese student is encouraged to share living accommodation with Canadian students.

All of the Japanese students naturally take the opportunity to "see the world" while they are participating in the exchange program. During the Christmas holidays from mid-December until early January, for example, students may go skiing in the Rocky Mountains, visit the house of Anne of Green Gables in Prince Edward Island, experience French-Canadian culture in Quebec City, or even holiday with their families in Hawaii. Upon completion of their second semester examination in mid-April, they can travel again for two more weeks before returning to Japan in early May.

\section{Waterloo/Kyoto Exchange Program}

A preliminary agreement regarding an official exchange program between the Faculties of Engineering at Waterloo and Kyoto Universities was signed in 1992. Although the Waterloo/Kyoto exchange program is open to both undergraduate and graduate students, thus far, both universities have decided to limit participation to graduate students only. The first two Master's students from Kyoto University arrived in Waterloo in early September 1995, and as of May 2002, a total of 28 Kyoto Master's students have participated. On the Canadian side, participation commenced in early April 1997 when one Canadian Master's student arrived in Kyoto. To date, three Canadian Master's students, all from the Department of Systems Design Engineering, have taken part in the program.

Program for Participating Graduate Students: The academic program for the Canadian and Japanese graduate students who take part in the Waterloo/Kyoto program is similar to that of the Tottori Master's students who go to Waterloo (see Section III-B). The students usually arrive at the host university at the start of the academic year-early September for the Japanese students going to Waterloo, and early April for the Canadians studying at Kyoto. The students normally study at the host university for two academic terms, during which time they can take courses for credit, or audit, and work on their research under the tutelage of host professors. Each Waterloo student going to Kyoto University is given a study desk in the laboratory of a professor working in his or her field of study, as is also the case with respect to Waterloo students studying in Tottori. Visiting students usually have desks alongside amicable host graduate students who are able to offer academic advice and invite them to participate in social activities. The exchange students have taken the opportunity to travel around the country in which they are living, and quite often, will visit nearby foreign countries such as, the United States, if they are in Canada, or Korea, if they are studying in Japan.

\section{PRINCIPLES FOR SUCCESS}

\section{A. Measures of Success}

As of August 2002, 132 Canadian and Japanese students have benefited from the two exchange programs described in Section III. So far, every participating exchange student has successfully completed his or her entire academic program at the host university, and for the case of the 80 undergraduate Waterloo students who have studied at Tottori University, each of these students has also obtained valuable work experience in Japan. Moreover, most of the graduate students learned new academic concepts at the host university that were directly incorporated into their graduate research theses, which were subsequently completed at their home universities. Every Japanese student has achieved fluency in English by the end of his or her sojourn in Canada, while each Canadian student has learned to converse reasonably well in Japanese, and write Japanese using the two phonetic alphabets, called hiragana and katakana, as well as some kanji (Chinese) characters. Additionally, each of the exchange students became totally immersed in the culture of the host country, formed many friendships, and took advantage of the opportunity to travel around the host country, and elsewhere. Finally, according to our knowledge, every past participant in the exchange program is now performing well in his or her chosen career path.

Much of the academic staff has also benefited from the exchange program by completing joint research projects with their foreign colleagues, and by visiting host universities to deliver 
invited research seminars and work on collaborative projects. There have been a number of spinoffs from the exchange programs that go well beyond the original purview of the agreements, and valuable academic and social networks are continuing to expand.

Another way to gauge the success of exchange programs is to examine how they have influenced the long-term careers and personal development of individual students. Accordingly, in July 1999, the authors initiated a survey of those students who had participated in the two exchange programs. The purpose of the written survey was to determine how the experience of living, studying, and perhaps also working in a foreign country influenced their careers and personal lives. Some individual success stories and survey results are given in Sections IV-B and C, respectively. Subsequently, basic principles required in creating, maintaining, and improving a successful exchange program are highlighted in Section V.

\section{B. Individual Success Stories}

Dr. Sakakibara was with the first group of Master's students from Kyoto University to go to the University of Waterloo, in September 1995. Through his graduate studies at Waterloo and Kyoto, Dr. Sakakibara gained a keen interest in doing research in environmental conflict management, as well as the confidence to tackle challenging research problems. Accordingly, after returning to Kyoto University he completed his Master's and Doctoral degrees. He is currently an Assistant Professor in the Department of Civil Engineering at Yamaguchi University in Ube, and is the head of a research laboratory. Dr. Sakakibara has already written a number of English and Japanese academic papers, and has presented many papers in English at international conferences.

Two Waterloo students became so enthralled with their undergraduate experiences in Japan under the Waterloo/Tottori exchange program, that they decided to take part in the Waterloo/Kyoto exchange program during their Master's degree. In particular, Possmayer went to Tottori University in 1992, and graduated with his Bachelor's degree in May 1994 from the Department of Systems Design Engineering. From May to August 1997, he spent a semester at Kyoto University as part of his Master's program in Systems Design Engineering. Upon graduation in May 1998, Possmayer went to Pakistan to work on rural energy and water development problems. From April to December, 1997, Zyzniewski went to Japan under the auspices of the Waterloo/Tottori agreement, and in May of 1998, she graduated with a Bachelor's degree in Civil Engineering from the University of Waterloo. In January 1999, Zyzniewski entered the Master's program in Systems Design Engineering and from mid-September 1999 until August 2000, she carried out research at Kyoto University on the topic of modeling tradable greenhouse gas emissions. She completed her Master's degree in May 2001, and is now employed with an engineering consulting firm.

Achieving fluency in a foreign language, and being exposed to a foreign culture, certainly helps to prepare engineering students to confront the challenges of the 21 st century, and allows them to participate effectively in the global marketplace. Consider, for instance, the astonishing careers of Tomoo Aoki and
Kazuo Uezumi, who came to Waterloo in 1991/92 during their Master's degree programs under the Waterloo/Tottori exchange program. After completing their Master's degrees in 1993, from the Department of Social Systems Engineering, both of these talented young men were hired by international consulting firms based in Japan. Specifically, Tomoo Aoki is working for Nihon Koei Consultants, based in Tokyo, which is a leading company specializing in infrastructure planning and management. Aoki has traveled extensively to countries in the Middle East and Southeast Asia, where he conducts all of his business in English. Kazио Uezumi is employed by Central Consultants International of Tokyo. He has helped to plan and develop port and harbour facilities in areas such as, Southeast Asia, Pacific Island Nations, and the Black Sea. English is required for all of his business dealings. It is interesting to note that because in recent times, Japanese engineering graduates often move from one company to another during their careers, rather than remain with one employer, Japanese corporations actively seek to employ undergraduate students who are participating in co-operative workterm programs, in order to entice them to join their companies after they have received their engineering degrees.

A number of Canadian students have returned to work in Japan, or other parts of Asia, as a direct result of their previous valuable educational and cultural experiences in Japan. For example, both Ian Clarke and Kenny Chow, who participated in the Waterloo/Tottori exchange program in 1993, returned to pursue careers in Japan, subsequent to graduating with Bachelor's degrees in Systems Design Engineering in 1995. Clarke is employed as an engineer in the systems design department of the Seiko Epson Corporation, at the Hirooka Office, located in Shoji City, Nagano Prefecture. Ian Clarke would eventually like to start a company in Canada that would be directly linked to Japan. Kenny Chow is working with the Bank of Montreal at its Japanese branch in Tokyo. Other engineering alumni from Waterloo who took part in the Waterloo/Tottori program include Bryan Mark and Daniel Kenny who are working for HSBC Securities Japan Limited in Tokyo, and Kris Jubandhu, employed by Fusion Consulting in Tokyo. All of the aforementioned individuals use both English and Japanese in their places of employment.

\section{Survey Results}

In July 1999, each of the Canadian and Japanese students who participated in the two exchange programs were mailed a questionnaire, either by post or email. Table I outlines the contents of the questionnaire sent to the Waterloo students. A similar form was forwarded to the Japanese exchange students, excluding the question related to any workterm experience as these students did not work while in Canada. After filling in background information in part I, each student was asked to respond in writing to the questions put forward in Section II. In the third part, each student simply circled his or her evaluation of each query. The key information from all three parts was tabulated in a spreadsheet while graphical output was produced for the third component.

Fig. 1 displays the ratings for each of the four queries listed at the bottom of Table I. These ratings were tabulated from questionnaires returned by 38 Waterloo engineering students who 
TABLE I

WATERLOO/TOTTORI EXCHANGE ProgRam QUeSTIONNAIRE
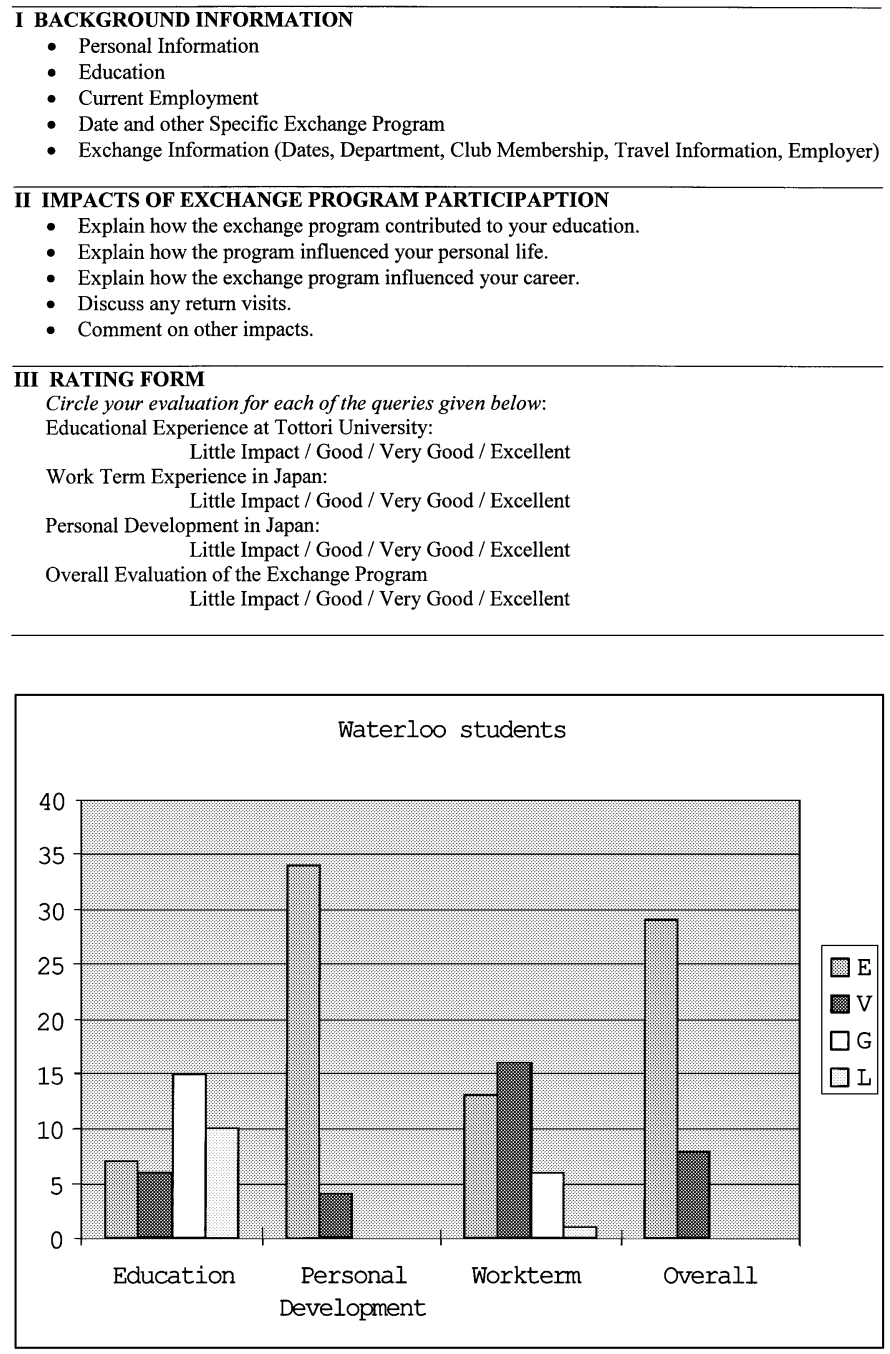

Fig. 1. Evaluation of the Waterloo/Tottori exchange program by participating Waterloo students. (Legend: E-Excellent, V-Very good, G-Good, and L-Little impact).

studied for the first semester of their third year at Tottori University, followed by a one-term job in a Japanese industry. As can be seen from the bar graph on the right in Fig. 1, a large majority of students felt that overall, the exchange program was excellent. In fact, $100 \%$ of the respondents rated the program as excellent, or else, very good. A pleasing, yet somewhat surprising result is the exchange students' assessment of their personal development while in Japan-34 out of 38, or about $90 \%$ of the respondents thought they had undergone significant personal development while living in Japan. As can be observed in Fig. 1, a majority of students evaluated their workterm experience in the very good and excellent categories. Finally, because engineering programs at Japanese and Canadian universities provide a similar set of courses in a given discipline or subject area, it is not unexpected that the educational experience of Waterloo students in Japan is not rated as highly as the other three categories of queries.

The Tottori and Kyoto Master's students, almost all of whom spent two semesters studying at the University of Waterloo, also gave very high ratings for the overall category, and for their personal development. One hundred percent of the Tottori students who responded to the questionnaire rated their educational experience at the University of Waterloo in the excellent, or very good categories, while $83 \%$ of the Kyoto students did likewise. One should keep in mind that the results shown in Fig. 1 for the Waterloo students studying at Tottori University are for undergraduate students, and not Master's students, which is the case for the Japanese students. The Japanese Master's students may have been impressed by the inclusion of the latest research results in graduate courses taught at Waterloo, as well as the freedom of thought expressed when discussing original research ideas.

Since both the Waterloo and Japanese students greatly appreciated their personal development while living in a foreign country, it is insightful to examine their written responses. Below are representative comments from Waterloo students who participated in the Waterloo/Tottori exchange program:

Bryan Mark works on equities trading for HSBC Securities Japan Limited in Tokyo. He went to Tottori in 1994 and he joyfully proclaims "I met my wife in Japan (Tottori). We are happily married and have a daughter." He also states that the exchange experience "provided more of a cultural education than a pure technical [one]."

Brian Wong is President of a software consulting company, Dezlang Systems Inc., located in Thornhill, Ontario. He participated in the exchange program in 1988, and speaks from his heart when he says, "I had one of the best times of my life on the exchange. It definitely influenced my life in terms of honesty, independence, generosity, balance, and respecting others."

Daniel Kenny is employed with HSBC Securities Japan Limited, in Tokyo, where he manages trading systems. As a result of living in Japan in 1994 he declares, "The exchange ultimately changed my life and I contribute my career progression and personal development over the last five years primarily to the experience gained from this outstanding exchange program."

Nimish Patel who now works as a systems analyst for the Bank of Montreal in Agincourt, Ontario, and participated in the Waterloo/Tottori exchange program in 1988, says that the experience "Provided a deep and rich appreciation and respect for the culture mosaic that influences our lives."

Adrienne Law completed the survey while she was still completing her undergraduate degree in Systems Design Engineering. For her workterm experience in Japan in 1998, she worked as a computer programmer for geographical information systems for the company, Nihon Suido Consultants. Ms. Law states, "I benefited from the exchange program in gaining a world perspective as well as learning about the Japanese culture, social structures and economy.... The welcome to Tottori University by faculty and students was very warm. International students are very well supported by the community."

James F. Kilpatrick is a partner in the firm Deloitte Consulting, located in Toronto, and specializes in management consulting with a focus on supply chain management. He was with the first group of Waterloo students to go to Tottori University in 1988, and states in his survey response, "I grew tremendously and learned a lot about the world. I gained a broader perspective and learned how to deal with new and unique situations." 
In their article on comparing systems engineering programs in the U.S., Brown and Scherer [1] put forward opportunities for improving the discipline of systems engineering by integrating information technology subjects into the systems engineering curriculae, as well as, putting more emphasis on systems analysis and design. They also conclude that job opportunities for systems engineering graduates, at both the undergraduate and graduate levels, will continue to grow faster than the economy into the foreseeable future. The results of our survey, completed mainly by systems engineering students, leads us to believe that an exchange program component in the educational experience of systems engineers promotes individual personal development, as well as a deep appreciation for the cultural values of others. Even if an engineering student of the future elects to pursue an individual-centered education, whereby he or she can access educational material, or multimedia coursework at any time and anywhere, as suggested by Tien [8], we believe that doing this while living in a foreign country will only further promote substantial character development.

\section{Principles and Reasons for Successful Exchange Programs}

Section III-A presents some key ingredients required in international exchange agreements, such as, the Waterloo/Tottori and Waterloo/Kyoto exchange programs described in detail in Sections III-B and C, respectively. Substantial evidence supporting the unqualified success of these two exchange programs is outlined in Sections IV-A-C. The objective of this section is to underscore the fundamental principles, not only embedded in the basic design of an exchange agreement, but also reflected in the practical implementation and enhancement of the exchange program as it evolves over time to meet the changing needs of students, academic staff, and even local communities. Experience has shown that adherence to these principles ensures continued success and long-term sustainability of a particular exchange program.

Culture-first Principle: Students and academic staff who enter an exchange program should be informed upfront that the overriding benefit, or purpose, for participation is to have the unique opportunity to learn about the traditions, history, language, work ethic, social behavior, and other cultural aspects of the foreign nation that they will be visiting. After all, the technical components of a university course, such as fluid mechanics, is identical in Japan, Canada, or in any other country. However, the pedagogy used in teaching fluid mechanics, the way research activities in fluid mechanics are structured and executed in research laboratories, the creative manners in which society uses technologies derived from theoretical fluid mechanics in its industrial and commercial activities, and the "fairness" rules by which ensuing wealth is equitably distributed among its citizens may be radically different in other societies. To help stimulate cultural interest in the country they will visit, exchange program applicants are requested to take language and cultural courses.

Champion Principle: In order for an exchange program between two universities to be successfully implemented and maintained, at least one fully dedicated faculty member is needed at each university to inspire both the program participants, and the staff who assist in the program's execution. In fact, the launching pad for the two Canada/Japan programs was the friendship between Hipel and Okada, that deepened over the years as a result of their joint research projects and many social interactions. Initially, these two friends constituted the sole "champions" for the exchange programs which they started, but later, others joined to assist in the venture. Furthermore, student interest in having an exchange program was the initial stimulus for founding the exchange programs in the first place. Subsequent to this demand, form and infrastructure naturally followed. Finally, the proponents ensured that the exchange programs were accepted at all administrative levels within their respective universities - departmental, faculty, and university levels.

Commitment Principle: Only those students and academic staff who have a strong desire to participate in an exchange program in order to reap cultural and academic benefits, should be permitted entrance to the program. For example, presently Tottori University can only accept a maximum of six Waterloo students per year, even though many more apply for admittance to the program. After a few friendly meetings with the program coordinators at Waterloo, the less serious "window shoppers" usually drop out by their own choice, and those who are keen to go to Japan remain in the program. Furthermore, as part of the application process, which includes completing a standard application form and providing a curriculum vitae, each applicant is required to write a letter explaining why he or she feels strongly about going to Japan. If the student also makes a firm commitment to study Japanese language and culture, he or she is formally accepted into the program subject to maintaining grades of over $70 \%$ in all ongoing coursework. Reverting back to Hideyoshi's principle quoted in Section I, a bird will only sing beautifully if it wants to sing, and likewise, a student will only achieve success in an exchange program if he or she is really motivated to participate, and for the right reasons. It is interesting to note that often the students with the highest grades have the most appreciation of the value of experiencing Japanese culture. As a further test of their commitment, students accepted into the program are expected to do most of the "leg work" in preparing material for visa applications, purchasing their air tickets, arranging for meetings with the coordinators, and maintaining electronic communication links with other applicants. Finally, new applicants and previous participants of an exchange program are encouraged to welcome Japanese visitors to Waterloo, include them in social activities, and assist them whenever requested.

Friendship Principle: An attitude of friendliness, consideration, and courtesy should be accorded to all people involved in the exchange program. This will result in healthy cooperation amongst all of the participants and a successful program. For instance, each Waterloo student will be warmly welcomed by a Japanese Professor who is working in the student's area of interest, and will gladly provide academic advice and other assistance. The student is also befriended by the Professor's graduate students, as well as by many other students and faculty members on campus. In both Japan and Canada, visitors are often invited to the homes of their hosts and given personal tours of 
local tourist sites. Following the example of the great Japanese Shogun, Toyotomi Hideyoshi, referred to in Section I, comradeship and friendly encouragement ultimately lead to success and avoid disharmony and conflict.

Self-supporting Principle: As explained in Section III-A, students are required to pay all direct costs of participation in the exchange program. However, as pointed out in Section IV, in recent years, both Japanese and Canadian students have been the fortunate recipients of generous scholarship support from Japanese institutions. Nonetheless, a given exchange program should be designed to operate without any type of external support in order to ensure its long-term economic survival. Of course, if grants and scholarships are offered, they should be graciously accepted.

Universality Principle: As stressed in Section IV-A, an exchange program should be made accessible to any keenly interested student having a proper academic background and acceptable grades as well as to any interested academic staff members. However, given that there are sufficient openings for participation, all people taking part should be in agreement with the relevant principles that are mentioned in this section.

Continuity Principle: To ensure success, a new exchange program should be launched immediately upon approval and should remain active every single year thereafter. Near the start, it may be necessary to take small steps, sending only a few students in order to get the fledgling program underway. The name of the game is "just do it." When program proponents adopt positive attitudes such as, perseverance, enthusiasm, the acceptance of responsibility, and the belief in what they are doing, they will continue to reap many academic benefits for all the participants as well as profit from unforeseen spinoffs.

Equality Principle: Visiting exchange students and faculty should be accorded all of the privileges and rights as corresponding people at the host university. Hence, qualified students can take appropriate courses from the host university and automatically receive credit for successfully completed courses transferred back to their home university. If visiting students are paying tuition fees at the host university, they should not be required to pay higher fees than the home students, and they should have equal access to facilities, such as, libraries, gymnasiums, cafeterias, residences, and computer systems. All ensuing costs will be borne by the visitors, but these costs will not be more than those charged to home students. Likewise, visiting researchers should be offered the same amenities as their colleagues at the host university. Finally, in some instances, certain exchange program agreements between two universities specify that the number of participating students from one university be the same as the number from the other. We deliberately do not embrace this type of equality concept into our exchange programs because we believe it contradicts the principle of flexibility.

Flexibility Principle: An exchange program can be viewed as a dynamic system, such as a biological entity that is genetically coded to accept unforeseen challenges as opportunities for changing, expanding, and maturing. In this way, it can meet academic expectations and demands as they arise and expand well beyond its original mandate. For instance, the spinoffs from the two exchange programs, including organizing international con- ferences and starting an exchange program between a Japanese and Canadian high school [4], demonstrate how this principle of flexibility can be adhered to in practice (for a detailed description of spinoffs, see [4]). Future possible developments that may occur include sending Waterloo graduate students to Japan to study at Tottori University, welcoming undergraduate exchange students to Waterloo, and also Kyoto, and creating better websites for the benefit of exchange student alumni and potential participants. In fact, by 2003, a university-wide agreement that includes many faculties beyond engineering, should be in place between Waterloo and Kyoto Universities. Just as it is often impossible to predict surprising advances in technology, it is also difficult to predict where the networking and spin offs from exchange programs could lead in the future. One thing we have learned is to be prepared for any eventuality, ranging from visiting interesting cultural sites, to the joint discovery of exciting ideas in research.

\section{Global Engineer In The ThiRd MillenNiUm}

At the start of his classic novel "A Tale of Two Cities," Dickens [3] wrote the prophetic statement, "It was the best of times, it was the worst of times." Indeed, these insightful phrases have as much relevance today as they did during the chaotic times of the French Revolution when the story in Dickens' well-loved novel took place. At the start of the third millennium, after Christ, the information age offers instant electronic access to mountains of data and knowledge, yet provides little guidance as to which particular information is worthy of digestion, or how we can make wise decisions based on this information. The international marketplace offers a plethora of merchandise for us to purchase but poisons our land, air, and water with its destructive by-products. More wealth is being created than ever before in history, yet the gap between the rich and the poor also continues to increase within an era of exponential population growth. Fortunately, the arms race between the superpowers is finally at an end, but regional wars are continually flaring up in many parts of the world. The U.S. has the most modern and well-prepared armed forces in the world, yet on September 11, 2001, New York City and Washington D.C. were subjected to deadly terrorist attacks. More and more people are becoming educated, but many feel helpless and frustrated as they are swept along by the strong winds of dramatic social and economic upheaval that are international in scope.

We firmly believe that proper education is the single most important long-term solution to creating a sustainable future for our world in which the benefits and responsibilities of globalization and modernization can be equitably shared across the globe by nation states, local communities, and individual citizens. We further feel that the internationalization of engineering education by means of exchange programs between countries, such as those described herein, constitutes one crucial way by which we can effectively educate and enlighten our youth. In fact, we regard it as a distinct privilege to assist our students to become "Global Engineers" who have a solid educational background in mathematics, science, engineering, information technology, decision analysis, systems thinking and design, as well as a keen sensitivity to the cultural diversity of a highly interconnected 
world through the first-hand experience of living, learning, and working in a foreign land. We intend to faithfully follow the sage advice of Hideyoshi, mentioned in Section I, by encouraging as many students and colleagues as possible to sing this beautiful song of international awareness and understanding which results from the participation in exchange programs.

\section{DEDICATION}

We are delighted to dedicate our paper in honor of Prof. Hideaki Noda, who, while Dean of Engineering at Tottori University, strongly supported the establishment of the Tottori/Waterloo Exchange Program, as well as other exchange programs and international cooperative ventures. Later as Vice-President Academic, he also energetically promoted international initiatives for the entire university community. After a long and illustrious career as a researcher in coastal engineering, teacher, and senior administrator, Prof. Hideaki Noda retired in March 2000, and subsequently became Vice-President and co-founder of a new university called Tottori Kankyo (Environmental) Daigaku (University). His many significant academic contributions, as well as his kind and considerate manner in dealing with others are greatly appreciated by his colleagues and students in Japan, Canada, and elsewhere.

We would also like to dedicate this paper to the memory of our dear friend and colleague Prof. Madan Singh who knew many of the people associated with the exchange programs described herein. Madan always treated the education of engineering students and the execution of leading-edge research as truly global activities. The characteristics of the University of Waterloo described in Section II-B-creativity, entrepreneurship and internationalization, reflect values that Madan held close to his heart. At the University of Waterloo's 1996 Spring Convocation, Singh was awarded the degree of Doctor of Engineering, Honaris Causa in recognition of his "Distinguished contributions not only to the intellectual core of systems engineering but also for very significant contributions to the development of the engineering profession as a whole."

\section{ACKNOWLEDGMENT}

The authors would like to express their sincere gratitude to the many people who have contributed to the success of the two Canada/Japan exchange programs, including in Canada, the late Prof. T. E. Unny, K. Ponnambalam, C. Kendrick, C. Seitz, V. Lawrence, H. Ratz, C. Howe, P. Roe, G. C. Brandt, J. Crossley, former Presidents D. Wright and J. Downey, President D. Johnston, former D. D. Burns, D. S. Chandhuri, B. Mitchell, M. Lango, and D. Knight at the University of Waterloo; and in Japan former Vice President Noda, President M. Michiue, former Presidents K. Takahashi, S. Hayashi, and A. Takagi, H. Kawai, H. Kita, S. Yamada, Y. Hosoi, Y. Okuyama, A. Kimura, K. Tanimoto, and K. Sugata at Tottori University; and President M. Nagao, former President H. Imura, I. Kimura, K. Kobayashi, H. Tatano, M. Sawai, and A. Fujita at Kyoto University; the various Japanese sponsors who generously provided scholarships for both Japanese and Canadian exchange students; the many Japanese companies who kindly employed exchange students from Canada; and A. Teratani and other members of the Chizu Creative Project Team. They also wish to thank our exchange program alumni for their enthusiasm and commitment in successfully completing their international studies, and for continuing to exemplify the exchange programs' ideals in their careers and personal lives.

\section{REFERENCES}

[1] D. E. Brown and W. T. Scherer, "A comparison of systems engineering programs in the united states," IEEE Trans. Syst., Man, Cybern. C, vol. 30, pp. 204-212, May 2002.

[2] P. J. Deshayes and W. A. H. Thissen, "Guest editorial, special section on systems engineering education," IEEE Trans. Syst., Man, Cybern. C, vol. 30, pp. 161-163, May 2000.

[3] C. Dickens, A Tale of Two Cities, All the Year Round, C. Dickens, Ed. London, U.K.: Serial form, 1859.

[4] K. W. Hipel, N. Okada, and K. Fukuyama, "Int. Exchange Programs Eng. Between University Waterloo Canada, Tottori, Kyoto Universities, Japan,” Dept. Sys. Design Eng., Univ. Waterloo, Waterloo, ON, Canada, SM-1 582 002, vol. N2L 3G1, 2002.

[5] J. H. G. Howard and H. C. Ratz, "The international engineering student exchange program at the university of waterloo," in Proc. Int. Gas Turbine Aeroengine Congress Exhibition, ASME, Orlando, FL, June 2-5, 1997.

[6] Kyoto University [Online]. Available: http://www.kyoto-u.ac.jp

[7] A. P. Sage, "Systems engineering education," IEEE Trans. Syst., Man, Cybern. C, vol. 30, pp. 164-174, May 2000.

[8] J. M. Tien, "Individual-centered education: An any one, any time, any where approach to engineering education," IEEE Trans. Syst., Man, Cybern. C, vol. 30, pp. 213-218, May 2002.

[9] Tottori University, Tottori, Japan [Online]. Available: http://www.tottori-u.ac.jp

[10] Univ. Waterloo, Waterloo, ON, Canada [Online]. Available: http://www.uwaterloo.ca

[11] E. Yoshikawa, Taiko, as translated to English from Japanese by Wilson. Tokyo, Japan: Kodansha, 1992.

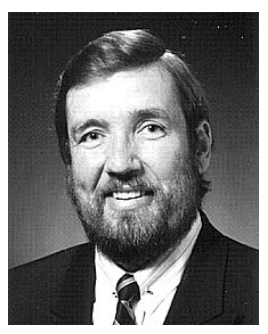

Keith W. Hipel (M'90-SM'92-F'96) is Professor of systems design engineering at the University of Waterloo, Waterloo, ON, Canada. His major research interests are the development and application of conflict resolution and time series analysis techniques from a systems design engineering perspective. The main application areas of these decision technologies are water resources management, hydrology, environmental engineering, and sustainable development. $\mathrm{He}$ is the author or co-author of four books, nine edited books, and more than 135 journal papers. Moreover, he is a Professional Engineer and has carried out consulting activities with engineering firms, government agencies, and utilities in many countries.

Dr. Hipel thoroughly enjoys teaching and is a recipient of the Distinguished Teacher Award. He is Fellow of the Royal Society of Canada (FRSC), Canadian Academy of Engineering (FCAE), Institute of Electrical and Electronics Engineers (FIEEE), and the American Water Resources Association (FAWRA). He is also a recipient of the Norbert Wiener Award from the IEEE Systems, Man and Cybernetics (SMC) Society, Outstanding Contribution Award from the IEEE SMC Society, W.R. Boggess Award from AWRA, and University of Waterloo Award for Excellence in Research. He is holder of a Canada Council Killam Research Fellowship and has also held a Monbusho Kyoto University Visiting Professor Position, Stanley Vineberg Memorial Visiting Professorship, Centre National de Ia Recherche Scientifique (CNRS) Research Fellowship, and Japan Society for Promotion of Science (JSPS) Fellowship. Finally, he is an Associate Editor of many international journals including the IEEE TRANSACTIONS ON SYSTEMS, MAN, AND CYBERNETICS, as well as Group Decision and Negotiation. 


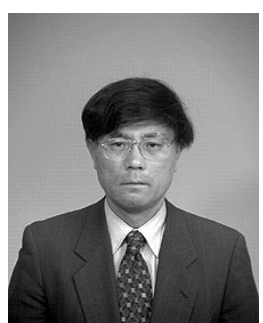

Norio Okada received the B.Eng. degree from the Department of Sanitary Engineering in 1970, the M.Eng. degree in 1972, and the Dr. Eng. degree in 1977, all from Kyoto University, Kyoto, Japan. He received an Honoris Causa honorary doctorate in Engineering from the University of Waterloo, Waterloo, ON, Canada, in 1996, and the Honorary Doctor of Engineering degree, from Chong Quing Communication University, China, in 1998.

$\mathrm{He}$ is currently Professor of Disaster Risk Management at the Disaster Prevention Research Institute (DPRI), Kyoto University. His major research interests are game theory, disaster and environmental risk management, and regional planning.

Dr. Okada is a member of the Japan Society of Civil Engineers (JSCE), Society of Risk Analysis, and the Japan Society of Hydrology and Water Resources, as well as many others organizations. In 1995, he received JSCE Research Awards for his application of game theory to cost allocation in water resources development.

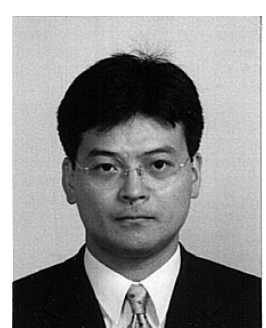

Kei Fukuyama received the Ph.D. degree in systems design engineering from the University of Waterloo, Waterloo, ON, Canada, in 1995.

He was among the first group of official exchange students from Tottori University, Tottori, Japan who traveled to Canada to study in the Master's program at the University of Waterloo for eight months, starting in September 1989. He is an Associate Professor of human-social information sciences in the Graduate School of Information Sciences, Tohoku University, Sendai, Japan. His research interests are in the development and application of game theory and other microeconomics techniques from a social systems engineering perspective. The main application areas are regional economic systems and environmental management systems, especially coordination problems among independent and conflicting individuals, regions, and other institutions. He also applies the decision technologies that he develops to the problem of effective enforcement of environmental laws and regulations. 